\title{
Clinical course and prognosis of acute post-traumatic coma
}

\author{
P. PAZZAGLIA, G. FRANK, F. FRANK, AND G. GAIST \\ From the Second Division of Neurosurgery, Ospedale Maggiore C.A. Pizzardi, Bologna, Italy
}

SYNOPSIS The clinical course and prognosis of 282 cases of acute post-traumatic coma have been studied. Death occurred in 140 cases $(49 \%$ ), and, of survivors, about two-thirds achieved complete social reintegration, while one-third were partially reintegrated or not at all. The quality of survival did not depend only on the nature of the physical sequelae, but also on other factors, particularly social ones. With regard to early prognosis, the authors believe it is possible to predict the final outcome of the patient by using the indices of age, level of coma, and the nature of the intracranial lesions.

A state of acute post-traumatic coma will follow one of the four following courses: (1) death; (2) recovery of consciousness with complete social reintegration; (3) recovery of consciousness without social reintegration or with partial reintegration; (4) prolonged coma (which may, in turn, move in the directions indicated in (1), (2), and (3). It would be extremely useful to establish the frequency with which these four possibilities occur, but studies on this subject are rare and contradictory.

Carlsson et al. (1968) studying a group of 496 cases of acute post-traumatic coma without surgically treatable lesions lasting more than 12 hours, observed that death ensued in $34.5 \%$ of the cases, complete mental recovery in $53.5 \%$, dementia in $11.5 \%$, and prolonged coma in $1 \%$.

Heiskanen and Sipponen (1970), in a study of 204 cases of post-traumatic coma lasting over 24 hours, reported a $50 \%$ incidence of death, $28.5 \%$ recovery, and $21.5 \%$ permanent invalidity.

Vigouroux et al. (1972), working with a population of adults with 'serious cranial trauma', reported the following statistics: death in $45.6 \%$ of the cases, survival without sequelae or with slight sequelae in $44 \%$, and survival with serious sequelae in $10.3 \%$.

The need for data which would enable us to predict the final outcome of a post-traumatic

(Accepted 9 August 1974.) coma, even in the earliest phases, is of the utmost practical importance.

The most commonly used parameters in this problem are: (1) age; (2) duration and depth of coma; (3) the nature of the intracranial lesions; (4) associated extracranial lesions and complications; and (5) electroencephalographic (EEG) findings obtained by either short or long (up to 24 hours) recordings (Gentile et al., 1967; Bergamasco et al., 1968; Bricolo et al., 1968, 1972; Carlsson et al., 1968; Goutelle and Mouret, 1970; Gutterman and Shenkin, 1970; Heiskanen and Sipponen, 1970; Vapalahti and Troupp, 1971; Vigouroux et al., 1972).

The heterogeneity of the populations in these studies and the diversity of aims (attempts to predict survival only or quality of survival) are not conducive to precise evaluation of the reliability of the prognostic indices. The present study has two objectives: (1) to determine the frequency of the different clinical courses of acute post-traumatic coma; (2) to establish the prognostic value, in quantitative terms, of indices found in the earliest stages of the disease.

\section{METHODS}

Patients were considered as 'comatose' if upon admission they were in a state of unresponsiveness from which no stimulus could arouse them, or if only repeated and energetic stimuli could cause arousal. In this second case, during the brief periods 49 
of provoked wakefulness patients were unable to answer questions verbally, but in some instances were able to obey simple orders. If they were not stimulated, they returned rapidly to their condition of unresponsiveness.

As one can see from these diagnostic criteria, our classification includes both patients who were strictly comatose (unarousable unresponsiveness) and patients who were stuporose (arousable unresponsiveness) (according to the classification of Plum and Posner, 1972).

We felt justified in including under the same heading two types of pathological alteration of consciousness, both because they have the same pathogenesis and also because they can often change from one to the other.

In a case evolving toward awakening, the end of the coma was considered to be the time when the patient became able to answer questions verbally, even if not always correctly. A similar criterion was also used by Carlsson et al. (1968).

The subjects of our study were 282 cases of acute post-traumatic coma admitted to this hospital in 1970 and 1971. Duration of coma was always over 24 hours, except in patients who died before this time without having regained consciousness. Hospitalization normally took place a few hours or a few days after the trauma, except in cases of coma secondary to chronic subdural haematoma. On admission all the patients underwent neuroradiological examinations consisting of direct examination of the skull and $a$ uni- or bilateral carotid arteriogram.

In order to evaluate the quality of social reintegration, all survivors underwent a follow-up examination at least two years after the trauma. This consisted of a neurological examination, a psychological examination, an EEG and a sociological evaluation of the quality of survival.

We then classified the survivors according to three categories:

S1: COMPLETE REINTEGRATION The patient leads the same social life as before the trauma;

S2: PARTIAL REINTEGRATION The patient occupies a lower socioprofessional position, but is still autonomous in his normal daily activities (dressing, eating, going out, etc.);

S3: NOT REINTEGRATED The patient is unable to support himself or take care of his own daily needs.

We used the following prognostic signs to attempt to foresee the three clinical courses and death: (1) the patient's age; (2) depth of coma on admission to the hospital (according to the classification proposed by Plum and Posner, 1972); (3) the nature of the intra- cranial lesions (according to the neuroradiological examinations and, for patients who underwent operations, the surgical findings).

\section{RESULTS}

CLINICAL COURSE The short and long clinical courses of 282 patients are summarized below:

1. Deceased: 140 patients $(49 \%)$.

2. Survivors: 142 patients $(51 \%)$, subdivided into:

$$
\begin{aligned}
& \text { S1: } 96 \text { patients }(34 \%) \\
& \text { S2: } 18 \text { patients }(6.3 \%) \\
& \text { S3: } 28 \text { patients }(10.7 \%)
\end{aligned}
$$

Mortality rate Of the 140 fatalities, 124 died during the acute phase of the coma, 10 during a state of prolonged coma subsequent to the acute phase, and six after reawakening; 108 patients (77\% of all fatal cases) died of the traumatic cerebral lesions, while $32(23 \%)$ died of extra-

TABLE 1

\begin{tabular}{|c|c|c|c|c|}
\hline \multirow[t]{2}{*}{ Phase of disease } & \multicolumn{2}{|c|}{ Cases } & \multicolumn{2}{|c|}{ Causes } \\
\hline & (No.) & $(\%)$ & $\begin{array}{c}\text { Cerebral } \\
(\text { No. })\end{array}$ & $\begin{array}{c}\text { Extracerebral } \\
\text { (No.) }\end{array}$ \\
\hline \multirow[t]{2}{*}{$\begin{array}{l}\text { During acute coma } \\
\text { During prolonged coma } \\
\text { After reawakening }\end{array}$} & $\begin{array}{r}124 \\
10 \\
6\end{array}$ & $\begin{array}{r}88.5 \\
7.1 \\
4.4\end{array}$ & $\begin{array}{r}101 \\
4 \\
3\end{array}$ & $\begin{array}{r}23 \\
6 \\
3\end{array}$ \\
\hline & 140 & 100.0 & $108(77 \%)$ & $32(23 \%)$ \\
\hline
\end{tabular}

RELATIONSHIP BETWEEN CAUSES OF DEATH AND PHASES OF DISEASE

TABLE 2

\begin{tabular}{|c|c|c|c|c|c|c|}
\hline \multirow{3}{*}{$\begin{array}{l}\text { Duration of } \\
\text { coma (days) }\end{array}$} & \multicolumn{2}{|c|}{ Cases } & \multicolumn{4}{|c|}{ Causes } \\
\hline & \multirow[t]{2}{*}{ (No.) } & \multirow[t]{2}{*}{$(\%)$} & \multicolumn{2}{|c|}{ Cerebral } & \multicolumn{2}{|c|}{ Extracerebral } \\
\hline & & & (No.) & $(\%)$ & (No.) & $(\%)$ \\
\hline $\begin{array}{l}\text { up to } 3 \\
4-7 \\
8-14 \\
\text { over } 15\end{array}$ & $\begin{array}{l}67 \\
23 \\
19 \\
25\end{array}$ & $\begin{array}{l}50.0 \\
17.0 \\
14.0 \\
18.6\end{array}$ & $\begin{array}{l}58 \\
20 \\
12 \\
15\end{array}$ & $\begin{array}{l}86.6 \\
87.0 \\
63.2 \\
60.0\end{array}$ & $\begin{array}{r}9 \\
3 \\
7 \\
10\end{array}$ & $\begin{array}{l}14.4 \dagger \\
13.0 \dagger \\
36.8 \ddagger \\
40.08\end{array}$ \\
\hline
\end{tabular}

RELATIONSHIP BETWEEN CAUSES OF DEATH AND DURATION OF COMA

* The six cases which died after reawakening have been excluded.

$\uparrow$ Especially associated traumatic lesions.

$\ddagger$ Especially acute renal insufficiency.

\& Especially bronchopulmonary infections. 
cranial lesions or complications ascribed to the trauma (Table 1).

Fifty per cent of all deaths occurred in the first three days after injury and were generally caused by the cerebral lesions. With the second week the extracranial lesions and complications took on increasing importance as the cause of death. They were responsible for $40 \%$ of the deaths occurring during and after the third posttraumatic week (Table 2).

Quality of survival The relationship between the quality of survival and the physical sequelae (neurological and extraneurological) is presented in Table 3.

TABLE 3

RELATIONSHIP BETWEEN QUALITY OF SURVIVAL AND PHYSICAL SEQUELAE

\begin{tabular}{lcccccc}
\hline \multirow{2}{*}{$\begin{array}{l}\text { Quality of } \\
\text { survival }\end{array}$} & \multicolumn{2}{c}{ Cases } & & \multicolumn{3}{c}{ Physical sequelae } \\
\cline { 2 - 3 } \cline { 5 - 7 } & $(N o)$. & $(\%)$ & & $(a)$ & $(b)$ & $(c)$ \\
\hline S1 & 96 & 67.6 & & 62 & 28 & 6 \\
S2 & 18 & 12.6 & & 5 & 5 & 8 \\
S3 & 28 & 19.7 & & 3 & 6 & 19 \\
\hline Total & 142 & 100.0 & 70 & 39 & 33 \\
\hline
\end{tabular}

(a) Absence of sequelae.

(b) Mild sequelae - that is, partial deficit of a cranial nerve, hypersomnia, hypomnesia, slight general decrease in mental efficiency, epilepsy with infrequent seizures, slight orthopaedic sequelae, etc.

(c) Marked sequelae - that is, total deficit of one or more cranial nerves, motor deficit of one or more limbs, language disturbances, amnesic syndrome, dementia, epilepsy with frequent seizures, severe orthopaedic sequelae, etc.

1. Ninety-six subjects were completely reintegrated into society $(67.6 \%$ of the survivors). We found, to our surprise, that in approximately one-third of these social recovery was not hampered by the presence of physical sequelae which, in six cases of this group, were marked.

2 . Eighteen subjects $(12.6 \%$ of the survivors) were reintegrated at a lower social level. This fact usually appeared to be related to the presence of physical sequelae, although there were five subjects in this group with no sequelae whatever.

3 . Finally, 28 subjects, about $20 \%$ of the survivors, had not achieved any significant degree of social reintegration. This negative outcome was usually due to the presence of severe physical sequelae; however, we were surprised to find that this group also included six subjects with mild sequelae and three with none at all.

EARLY PROGNOSIS Prognostic value of age The relationship between age and the clinical course of the coma is shown in Table 4. This demon-

TABLE 4

RELATIONSHIP BETWEEN PATIENT'S AGE AND CLINICAL COURSE OF DISEASE

\begin{tabular}{|c|c|c|c|c|c|c|c|}
\hline \multirow{3}{*}{$\begin{array}{l}\text { Age } \\
(y r)\end{array}$} & \multicolumn{7}{|c|}{ Clinical course } \\
\hline & \multicolumn{2}{|c|}{$S I$} & \multicolumn{2}{|c|}{$S 2+S 3$} & \multicolumn{2}{|c|}{ Death } & \multirow{2}{*}{$\begin{array}{l}\text { Total } \\
\text { (No.) }\end{array}$} \\
\hline & (No.) & $(\%)$ & $(N o)$. & $(\%)$ & (No.) & $(\%)$ & \\
\hline $\begin{array}{l}0-10 \\
11-20 \\
21-40 \\
41-60 \\
\text { over } 61\end{array}$ & $\begin{array}{l}17 \\
28 \\
15 \\
22 \\
14\end{array}$ & $\begin{array}{l}60.7 \\
46.6 \\
30.0 \\
29.0 \\
20.5\end{array}$ & $\begin{array}{r}1 \\
7 \\
15 \\
15 \\
8\end{array}$ & $\begin{array}{r}3.5 \\
11.6 \\
30.0 \\
19.5 \\
11.7\end{array}$ & $\begin{array}{l}10 \\
25 \\
20 \\
39 \\
46\end{array}$ & $\begin{array}{l}35.7 \\
41.6 \\
40.0 \\
51.3 \\
67.6\end{array}$ & $\begin{array}{l}28 \\
60 \\
50 \\
76 \\
68\end{array}$ \\
\hline Total & 96 & 34.0 & 46 & 17.0 & 140 & 49.0 & 282 \\
\hline
\end{tabular}

General $\chi^{2}=16.88 ; \mathrm{P}<0.001$ (S1 vs. Death).

Regression $\chi^{2}=16.67 ; P<0.001$ (age groups are given the scores 0-1-2-3-4).

Deviation from regression $x^{2}=0.13 ; \mathrm{P}>0.05$.

$\chi^{2}=11.37 ; \mathrm{P}<0.001$ ( $\mathrm{S} 1$ vs. Death grouping cases under and over 40 years).

strates that age very clearly influences the clinical course with regard to both mortality rate and quality of survival. The age of 20 years is the positive limit for complete recovery, since under this age the percentage of subjects who recover is substantially higher than that of the general average. The age of 40 years represents the positive limit for survival alone as under this age the death rate is below that of the general average. After age 60 years the probability of dying is clearly greater than that of surviving: indeed, $68 \%$ of the subjects in this category died.

Prognostic value of level of coma The relationship between the level of coma and the clinical course is indicated in Table 5. It may be seen that the more caudal the level of the injury responsible for the coma, the more malignant the clinical course will be. In diencephalic and uncal syndromes the probability of recovery is above average. In mesencephalic syndrome the 
TABLE 5

RELATIONSHIP BETWEEN LEVEL OF COMA AND CLINICAL COURSE

\begin{tabular}{|c|c|c|c|c|c|c|c|}
\hline \multirow[t]{3}{*}{ Coma level } & \multicolumn{7}{|c|}{ Clinical course } \\
\hline & \multicolumn{2}{|c|}{$S 1$} & \multicolumn{2}{|c|}{$S 2+S 3$} & \multicolumn{2}{|c|}{ Death } & \multirow{2}{*}{$\begin{array}{l}\text { Total } \\
\text { (No.) }\end{array}$} \\
\hline & (No.) & $(\%)$ & (No.) & $(\%)$ & (No.) & $(\%)$ & \\
\hline $\begin{array}{l}\text { Diencephalic } \\
\text { Uncal } \\
\text { Mesencephalic } \\
\text { Bulbopontine } \\
\text { Coma depassé }\end{array}$ & $\begin{array}{r}82 \\
10 \\
4 \\
- \\
-\end{array}$ & $\begin{array}{l}44.3 \\
37.0 \\
10.0 \\
- \\
-\end{array}$ & $\begin{array}{r}37 \\
7 \\
2 \\
- \\
-\end{array}$ & $\begin{array}{r}20.0 \\
26.0 \\
5.0 \\
- \\
-\end{array}$ & $\begin{array}{r}66 \\
10 \\
35 \\
20 \\
9\end{array}$ & $\begin{array}{r}35.6 \\
37.0 \\
85.0 \\
100.0 \\
100.0\end{array}$ & $\begin{array}{r}185 \\
27 \\
41 \\
20 \\
9\end{array}$ \\
\hline
\end{tabular}

clinical course is usually unfavourable; only $10 \%$ of the cases which reach this level of coma will recover completely. Bulbopontine syndrome and coma depassé always have a bad outcome.

Prognostic value of nature of intracranial lesions Table 6 shows the clinical course of two groups of patients-those with surgically treatable intracranial lesions and those without. It is evident that surgical lesions, generally speaking, involve a less favourable prognosis than non-surgical lesions.

\section{TABLE: 6}

RELATIONSHIP BETWEEN NATURE OF INTRACRANIAL LESIONS AND CLINICAL COURSE

\begin{tabular}{|c|c|c|c|c|c|c|c|}
\hline \multirow{3}{*}{$\begin{array}{l}\text { Nature of } \\
\text { lesions }\end{array}$} & \multicolumn{7}{|c|}{ Clinical course } \\
\hline & \multicolumn{2}{|c|}{$S 1$} & \multicolumn{2}{|c|}{$S 2+S 3$} & \multicolumn{2}{|c|}{ Death } & \multirow{2}{*}{$\begin{array}{l}\text { Total } \\
\text { (No.) }\end{array}$} \\
\hline & (No.) & $(\%)$ & (No.) & $(\%)$ & (No.) & $(\%)$ & \\
\hline $\begin{array}{l}\text { Non-surgical } \\
\text { Surgical }\end{array}$ & $\begin{array}{l}50 \\
46\end{array}$ & $\begin{array}{l}43.0 \\
27.7\end{array}$ & $\begin{array}{l}18 \\
28\end{array}$ & $\begin{array}{l}15.5 \\
16.8\end{array}$ & $\begin{array}{l}48 \\
92\end{array}$ & $\begin{array}{l}41.5 \\
55.5\end{array}$ & $\begin{array}{l}116 \\
166\end{array}$ \\
\hline
\end{tabular}

$x^{2}=6.71 ; \mathrm{P}<0.01$ (S1 vs. Death).

Table 7 indicates that chronic subdural haematoma is an exception to this rule as its prognosis is generally benign. The Table also suggests that, within the sphere of surgical lesions, it is possible to establish a scale of decreasing severity with acute subdural haematoma in the first place, followed by lacerations and contusions and acute extradural haematoma.
TABLE 7

SEVERITY SCALE FOR SURGICAL LESIONS

\begin{tabular}{|c|c|c|c|c|c|c|c|}
\hline \multirow[t]{2}{*}{ Type of lesion } & \multicolumn{2}{|c|}{$S I$} & \multicolumn{2}{|c|}{$S 2+S 3$} & \multicolumn{2}{|c|}{ Death } & \multirow{2}{*}{$\begin{array}{l}\text { Total } \\
\text { No. }\end{array}$} \\
\hline & (No.) & $(\%)$ & (No.) & $(\%)$ & (No.) & $(\%)$ & \\
\hline $\begin{array}{l}\text { Acute subdural } \\
\text { haematoma } \\
\text { Lacerations and }\end{array}$ & 7 & 24.4 & 1 & 3.1 & 21 & 72.5 & 29 \\
\hline $\begin{array}{l}\text { contusions } \\
\text { Acute extradural }\end{array}$ & 23 & 22.5 & 19 & 18.5 & 60 & 59.0 & 102 \\
\hline $\begin{array}{l}\text { haematoma } \\
\text { Chronic subdural }\end{array}$ & 7 & 29.0 & 6 & 25.0 & 11 & 46.0 & 24 \\
\hline haematoma & 9 & 82.0 & 2 & 18.0 & 一 & - & 11 \\
\hline
\end{tabular}

Prognostic value of association of three parameters: age, level of coma, and nature of intracranial lesions To increase the prognostic value of these three parameters, we have correlated the final outcome of the coma with the association of the various factors. For this purpose each parameter was subdivided into two sections, one with a favourable ('positive') prognostic value and the other unfavourable ('negative'). We considered an age under 40 years as positive and over 40 years as negative. Regarding level of coma, we considered diencephalic and uncalo syndromes as positive and the other three as negative. With regard to the nature of the lesions, we gave the absence of surgically treatable lesions a positive value and their presence a.? negative one (with cases of chronic subdural haematoma excluded). In this way, the population is divided into eight prognostic categories as shown in Tables 8 and 9.

It may be deduced from Table 8 that the patients in categories characterized by the presence of diencephalic or uncal syndromes usually have a favourable prognosis if they are not over 40 years old and suffering from surgical lesions. In the latter case there is only a $15 \%$ chance of complete recovery and the mortality rate is $63 \%$.

Table 9 demonstrates that patients with mesencephalic or bulbopontine syndromes or coma depassé almost always have a bad prognosis. Only patients with a mesencephalic syndrome under 40 years of age have some chance of recovering.

\section{DISCUSSION}

Acute post-traumatic coma led to death in 
TABLE 8

CLINICAL COURSE OF DIENCEPHALIC AND UNCAL SYNDROMES COMPARED WITH PATIENT'S AGE AND NATURE OF LESIONS

\begin{tabular}{|c|c|c|c|c|c|c|c|}
\hline \multirow{3}{*}{$\begin{array}{l}\text { Age }(y r) \text { and } \\
\text { nature of lesions }\end{array}$} & \multicolumn{7}{|c|}{ Clinical course } \\
\hline & \multicolumn{2}{|c|}{$S 1$} & \multicolumn{2}{|c|}{$S 2+S 3$} & \multicolumn{2}{|c|}{ Death } & \multirow{2}{*}{$\begin{array}{l}\text { Total } \\
\text { (No.) }\end{array}$} \\
\hline & (No.) & $(\%)$ & (No.) & $(\%)$ & (No.) & $(\%)$ & \\
\hline \multicolumn{8}{|l|}{ Under 40} \\
\hline Non-surgical & 33 & 63.4 & 12 & 23.0 & 7 & 13.6 & 52 \\
\hline Surgical & 26 & 57.7 & 9 & 20.0 & 10 & 22.3 & 45 \\
\hline \multicolumn{8}{|l|}{ Over 40} \\
\hline Non-surgical & 15 & 39.4 & 6 & 16.0 & 17 & 44.6 & 38 \\
\hline Surgical & 10 & 15.0 & 15 & 22.0 & 42 & 63.0 & 67 \\
\hline
\end{tabular}

$\chi^{2}=34.76 ; \mathrm{P}<0.001$ (S1 vs. Death grouping cases under and over 40 years).

$\chi^{2}=0.63 ; \mathrm{P}>0.05$ (non-surgical $v s$. surgical in the group of cases under 40 years).

$x^{2}=5.97 ; \mathrm{P}<0.02$ (non-surgical vs. surgical in the group of cases over 40 years).

\section{TABLE 9}

CLINICAL COURSE OF MESENCEPHALIC AND BULBOPONTINE SYNDROMES AND COMA DEPASSÉ COMPARED WITH PATIENT'S AGE AND NATURE OF LESIONS

\begin{tabular}{|c|c|c|c|c|c|c|c|}
\hline \multirow{3}{*}{$\begin{array}{l}\text { Age }(y r) \text { and } \\
\text { nature of lesions }\end{array}$} & \multicolumn{7}{|c|}{ Clinical course } \\
\hline & \multicolumn{2}{|c|}{$S 1$} & \multicolumn{2}{|c|}{$S 2+S 3$} & \multicolumn{2}{|c|}{ Death } & \multirow{2}{*}{$\begin{array}{l}\text { Total } \\
\text { (No.) }\end{array}$} \\
\hline & (No.) & $(\%)$ & (No.) & $(\%)$ & (No.) & $(\%)$ & \\
\hline \multicolumn{8}{|l|}{ Under 40} \\
\hline Non-surgical & 2 & 11.0 & 一 & - & 16 & 89.0 & 18 \\
\hline Surgical & 1 & 4.2 & 1 & 4.2 & 22 & 91.6 & 24 \\
\hline \multicolumn{8}{|l|}{ Over 40} \\
\hline Non-surgical & - & - & - & - & 8 & 100.0 & 8 \\
\hline Surgical & - & 一 & 1 & 5.3 & 18 & 94.7 & 19 \\
\hline
\end{tabular}

approximately one-half of the cases we studied. A similar mortality rate was reported by Heiskanen and Sipponen (1970) and Vigouroux et al. (1972). The lower death rate $(34.5 \%)$ cited by Carlsson et al. (1968) is probably due to the fact that they selected only coma cases without surgically treatable lesions, and these cases, as our study shows, have a better prognosis. The traumatic cerebral lesions are responsible for death in about threequarters of the cases and their effects are most evident in the course of the first posttraumatic week. The extracranial causes of death (responsible for about one-quarter of the deaths) are usually seen beginning with the second week. Similar results were observed by Carlsson et al. (1968) (one-sixth of the deaths among their patients were extraneurological) and by Heiskanen and Sipponen (1970) (one-third of the deaths were extraneurological).

These findings demonstrate that acute posttraumatic coma does not fall exclusively within the scope of neurosurgery, but is a borderline condition which requires the early and active participation of a large team of specialists (in addition to neurosurgeons and anaesthetists, general surgeons, orthopaedic and kidney specialists, cardiologists, and so on).

About one-half of the cases survive the coma and regain consciousness. Of these, about twothirds achieve complete social reintegration, while about one-third do not return to society or are only partially reintegrated.

The quality of survival does not depend directly on the presence or nature of the physical sequelae, as subjects with severe sequelae may be well integrated in society while others without sequelae do not achieve any degree of reintegration.

A similar observation was made by Cohadon et al. (1972) in a study of 190 subjects who had survived traumatic coma and were placed in a rehabilitation centre. In the opinion of these authors a direct correlation between the quality of the recovery and the nature of the sequelae exists only in the presence of very severe sequelae, which involved only one-fifth of their patients. These findings indicate that the process of resocialization is conditioned not only by the sequelae, but also by other factors, especially those of a psychosocial nature. This confirms once again the multidisciplinary dimension of the problem of traumatic coma; just as these patients need the active efforts of the emergency team during the acute phase, so during the regression phase and after regaining consciousness, they need a full rehabilitation team, in particular psychosocial workers.

EARLY PROGNOSIS The results of our research demonstrate that it is possible to arrive at a prognostic opinion even in the earliest phases of the coma by using the indices of age, level of coma, and the nature of the intracranial lesions. These results may be summarized as follows:

1. The lower the age and the more rostral the level of the lesion responsible for the coma, the more favourable is the prognosis with regard to 
both the death rate and the quality of survival. These observations are in agreement with those of numerous other authors (Gentile et al., 1967; Carlsson et al., 1968; Goutelle and Mouret, 1970; Heiskanen and Sipponen, 1970; Vapalahti and Troupp, 1971; Vigouroux et al., 1972).

Surgically treatable lesions involve a less favourable prognosis than non-surgically treatable ones, with the exception of chronic subdural haematoma.

2. Complete recovery is possible only for patients with diencephalic or uncal syndromes, whatever their age, and for those with mesencephalic syndrome who are under 40 years of age.

3. In our group of patients, all those over 40 years old with mesencephalic syndrome and all those with bulbopontine syndrome or coma depassé (whatever the age) had unsatisfactory, and almost always fatal outcomes.

These conclusions should not be construed as licence to refrain from giving therapy to the patients for whom a bad outcome is likely, but they should rather stimulate an intensification of our effort to prevent the coma from reaching the point of no return. Since the lesion in the brainstem responsible for mesencephalic and bulbopontine syndromes is rarely a direct consequence of the trauma but more often secondary to transtentorial herniation (Plum and Posner, 1972), every effort should be directed at preventing this complication.

The authors wish to acknowledge the cooperation of $\mathrm{Dr}$ A. Manzini, of the Institute of Pharmacology, University of Bologna, for the statistical analysis of the data.

\section{REFERENCES}

Bergamasco, B., Bergamini, L., Doriguzzi, T. (1968). Clinical value of the sleep electroencephalographic patterns in posttraumatic coma. Acta Neurologica Scandinavica, 44, 495511.

Bricolo, A., Gentilomo, A., Rosadini, G., and Rossi, G. F. (1968). Long-lasting post-traumatic unconsciousness. A study based on nocturnal EEG and polygraphic recording. Acta Neurologica Scandinavica, 44, 512-532.

Bricolo, A., Turella, G., Signorini, G. C., Mazza, C., Grosslercher, C., and Dalle Ore, G. (1972). Valore prognostico dell'EEG nella fase acuta del coma traumatico. Rivista Neurologia, 42, 213-218.

Carlsson, C.-A., Essen, C. von, and Löfgren, J. (1968). Factors affecting the clinical course of patients with severe head injuries. Part I: Influence of biological factors. Part 2: Significance of posttraumatic coma. Journal of Neurosurgery, 29, 242-251.

Cohadon, F., Hubert, I. M., and Richer, E. (1972). Fréquence des séquelles et problèmes qu'elles posent durant le processus de réhabilitation. Neurochirurgie, 18, Suppl. 2, 209-217.

Gentile, S. L., Perria, L., Rivano, C., Rossi, G. F., and Viale, G. (1967). Trattamento chirurgico e prognosi nelle lesioni cerebrali traumatiche. Sistema Nervoso, 19, 217-227.

Goutelle, A., and Mouret, Ph. (1970). Le pronostic des traumatismes crâniens. Acta Psychiatrica Belgica, 70, 445482.

Gutterman, P., and Shenkin, H. A. (1970). Prognostic features in recovery from traumatic decerebration. Journal of Neurosurgery, 32, 330-335.

Heiskanen, O., and Sipponen, P. (1970). Prognosis of severe brain injury. Acta Neurologica Scandinavica, 46, 343-348.

Plum, F., and Posner, J. B. (1972). The Diagnosis of Stupor and Coma, 2nd edn. Davis: Philadelphia. Vapalahti, M., and Troupp, H. (1971). Prognosis for patients
with severe brain injuries. British Medical Journal, 3, 404407.

Vigouroux, P. R., Baurand, C., Choux, M., and Guillermain, P. (1972). État actuel des aspects séquellaires graves dans les traumatismes crâniens de l'adulte. Neurochirurgie, 18, Suppl. 2. 